\title{
Incidence of fractures in a geographically defined population
}

\author{
Liam J Donaldson, Amanda Cook, Richard G Thomson
}

\begin{abstract}
Study objective-The aim was to describe the population based age and sex specific incidence of fractures at different sites in a large English health district.

Design-Recording of fractures was accomplished by a specially constructed outpatient index and by record linkage to hospital inpatient information, for the three years surrounding the 1981 census.

Setting-The fracture index was held by the Department of Community Health in Leicester using data from the fracture clinic at the central large district general hospital, supplemented by hospital inpatient data from Trent Region and the two adjoining regions.
\end{abstract}

Participants-The denominator population was the Leicestershire Health Authority resident population. In the three years, 12711 fractures amongst males and 10565 amongst females were recorded.

Measurements and main results-The overall estimated annual incidence of fractures was 100 per 10000 population for males and 81 per 10000 population for females. Below the age of 55 years all fractures showed a higher incidence amongst males but amongst the over $55 \mathrm{~s}$, there was a consistent fall in the male:female incidence ratio with some sites showing a striking female preponderance. The results also show an apparent age specific temporal increase in incidence at certain fracture sites compared with earlier British data, but fracture incidence figures still suggest lower rates in this country than in North America and some Scandinavian countries.

Conclusions-These findings provide population based incidence data on a major public health problem and are consistent with the major determinants of osteoporosis and increase in falls in postmenopausal women. The temporal and geographical variation in fracture incidence remain to be explained.

Northern Regional

Benfield Road,

Walkergate, Newcastle

upon Tyne NE6 4PY,

United Kingdom

L J Donaldson

R G Thomson

Department of

Community Health,

University of

Leicester School of

Medicine, Leicester,

United Kingdom

A Cook

Correspondence to:

Professor Donaldson

Accepted for publication January 1990
Fractures are an important though not fully quantified part of the workload of the hospital service: in 1985 there were an estimated 180000 admissions for treatment of fractures in England; ${ }^{1}$ outpatient diagnostic data are not routinely available but it is undoubtedly the case that many more people with fractures are treated on an outpatient basis than as inpatients.

The absence of basic descriptive epidemiological data on the frequency and distribution of fractures in the population is serious and hampers the elucidation of the public health problem presented by this common injury.

Most published epidemiological studies use an early British population based study ${ }^{2}$ as the benchmark for comparing their own findings, though many such studies are essentially hospital case series. Thus, since the findings of the study ${ }^{2}$ conducted in Dundee and Oxford in the 1950s under the auspices of the Medical Research Council, there have been no comparable British data on the pattern of fracture incidence in a defined population. Moreover, even this early study was limited to the population over the age of 35 years.

It is difficult to generalise from more recent population based studies carried out in other countries, even where detection rates have been very good ${ }^{\text {eg } 3-5}$ because of differences in the nature of the population at risk in terms of factors such as social class or predisposing environmental conditions.

The present study seeks to provide an estimate of the incidence of fractures (at various sites) and at all ages in a mixed urban and rural British community and to examine the influence of age and sex, particularly in relation to likely pre- and postmenopausal effects on specific fractures.

\section{Methods}

POPULATION AND DATA COLLECTION

The study population was Leicestershire, the largest health district in England, a mixed urban and rural population of approximately 850000 . It lies at the southernmost tip of the Trent Region, one of 14 such health regions in the country. The organisation of services in Leicestershire is well suited to the epidemiological study of orthopaedic conditions. A high proportion of the residents of this large population who sustain injuries are treated in a single accident and emergency department based in a centrally situated district general hospital. Non-traumatic orthopaedic cases are dealt with in two other hospitals in the city.

A computerised diagnostic index based on fracture clinic attenders was established by the Department of Community Health, University of Leicester, working in conjunction with the Division of Orthopaedics of the Leicestershire Health Authority. The "fracture clinic" is an important part of most orthopaedic and trauma services: it is an outpatient service and, in Leicestershire, clinics take place each weekday and are attended by patients who have been in the Accident and Emergency Department during the previous day or night with fractures, suspected fractures, or other injuries deemed to need the opinion of, or treatment by, an orthoapedic surgeon. The fracture clinic also derives cases from 
some of the patients who have been admitted for hospital inpatient care because of trauma and require follow up after discharge.

Data recorded on each patient, and contained in the index, included demographic information, details of their attendances, and diagnostic and treatment data. The first two categories of information were recorded in a standard way by clinic administrative staff and the clinical data were recorded by senior or junior surgical staff. All data were encoded by two specially trained coding staff who were dedicated solely to this task. In the case of diagnostic data, the ninth Revision of the International Classification of Diseases (ICD9) was used. ${ }^{6}$ Each patient entered into the index was allocated a unique identification number which was reallocated to them on future attendances even for subsequent episodes of care unrelated to their first entry on to the index.

The collection of data by the fracture index has been ongoing since 1979 , with the first complete year of coverage being 1980 . The complexities of linkage to routinely collected data on orthopaedic inpatients were considered too great to be undertaken on a permanent basis. However, for the three year period surrounding the last national population census in 1981, a special linkage exercise has been carried out for patients who sustained fractures (ICD9 numbers 800 to 829 ) using data for the outpatient fracture index and routinely available inpatient data on orthopaedic and trauma patients retrieved from hospital activity analysis (collected on a regional basis).

Listings of inpatients treated for fractures in Leicestershire hospitals, other hospitals within the Trent region, and (by contact with the statistical divisions of the corresponding regional health authorities) hospitals in the two other regions which adjoin Leicestershire were obtained. These were searched manually against fracture clinic patients and duplicate entries were eliminated, as were entries from inpatients who had been readmitted.

Although fairly comprehensive, this method will have fallen short of identifying every single fracture which occurred amongst residents of Leicestershire. It will have excluded the following main groups: outpatients treated with fractures in districts surrounding Leicestershire (no routine data available); people who sustained fractures in other parts of the country and did not return for any follow up treatment within the Leicestershire district; people who sustained fractures and were not aware of having done so; people with fractures who were treated exclusively by their general practitioners; people who died with an unsuspected or undiagnosed fracture; and patients who were discharged directly from the accident and emergency department without being given an appointment for the next day's fracture clinic. We believe that these categories were relatively small, although in the final category a larger proportion of minor fractures (eg, phalanges of the foot) may have eluded the register. The data for spinal fractures may also underestimate the true incidence, particularly as many vertebral fractures may have a gradual or even painless onset, making incidence studies extremely problematic. ${ }^{7}$ Notwithstanding, we consider that the resulting data approximate to a register of fractures which occurred amongst residents of Leicestershire during the three year period concerned.

\section{STATISTICAL ANALYSIS}

The $95 \%$ confidence interval for the $\log _{n}$ ratio of male to female fracture incidence was calculated using the formula:

$$
95 \% \mathrm{CI}=1.96 \times(1 / \mathrm{f}+1 / \mathrm{m})^{1 / 2}
$$

where $f$ and $m$ are the number of fractures for women and men at the given site.

\section{Results}

The total number of fractures of all types registered for the three year period was 12711 amongst males and 10565 amongst females, giving estimated average annual incidence rates per 10000 population of 100 (males) and 81 (females).

As figure 1 shows, in females, despite a peak of incidence in early childhood, the age specific

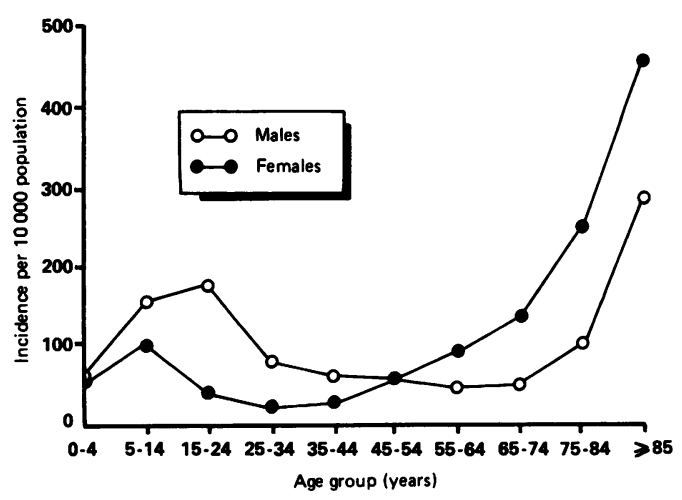

Figure 1 Average annual fracture incidence rate per 10000 population, by age group and sex.

fracture incidence rates remained below the corresponding male rates until late middle age when the female age groups showed successively higher values than the males. It can also be seen from fig 1 that there was a more sustained peak of incidence earlier in life for males with the incidence rate per 10000 population for young men aged 15-24 years (178) slightly exceeding that for boys aged 5-14 years (160). Although the commonest fracture site in both males and females was the lower end of the radius and ulna (table I), there were many differences between the sexes in the frequency at which fractures occurred at particular sites; for example, fractured neck of femur was the second most common site of fracture amongst women of all ages, while in males it was the 10th most common. In men, metacarpal fractures were the second most common whilst amongst women they were amongst the least common.

The age and sex specific incidence varied markedly according to the site of the fracture and some examples are shown in fig 2 . It can be seen, for example, that fracture of the neck of the femur showed a very low incidence in childhood and early adult life, with a steadily increasing rate for both sexes from middle age upwards, with a high incidence amongst women (fig 2A). Apart from a small peak in childhood, fractures of the upper humerus followed a broadly similar age and sex 

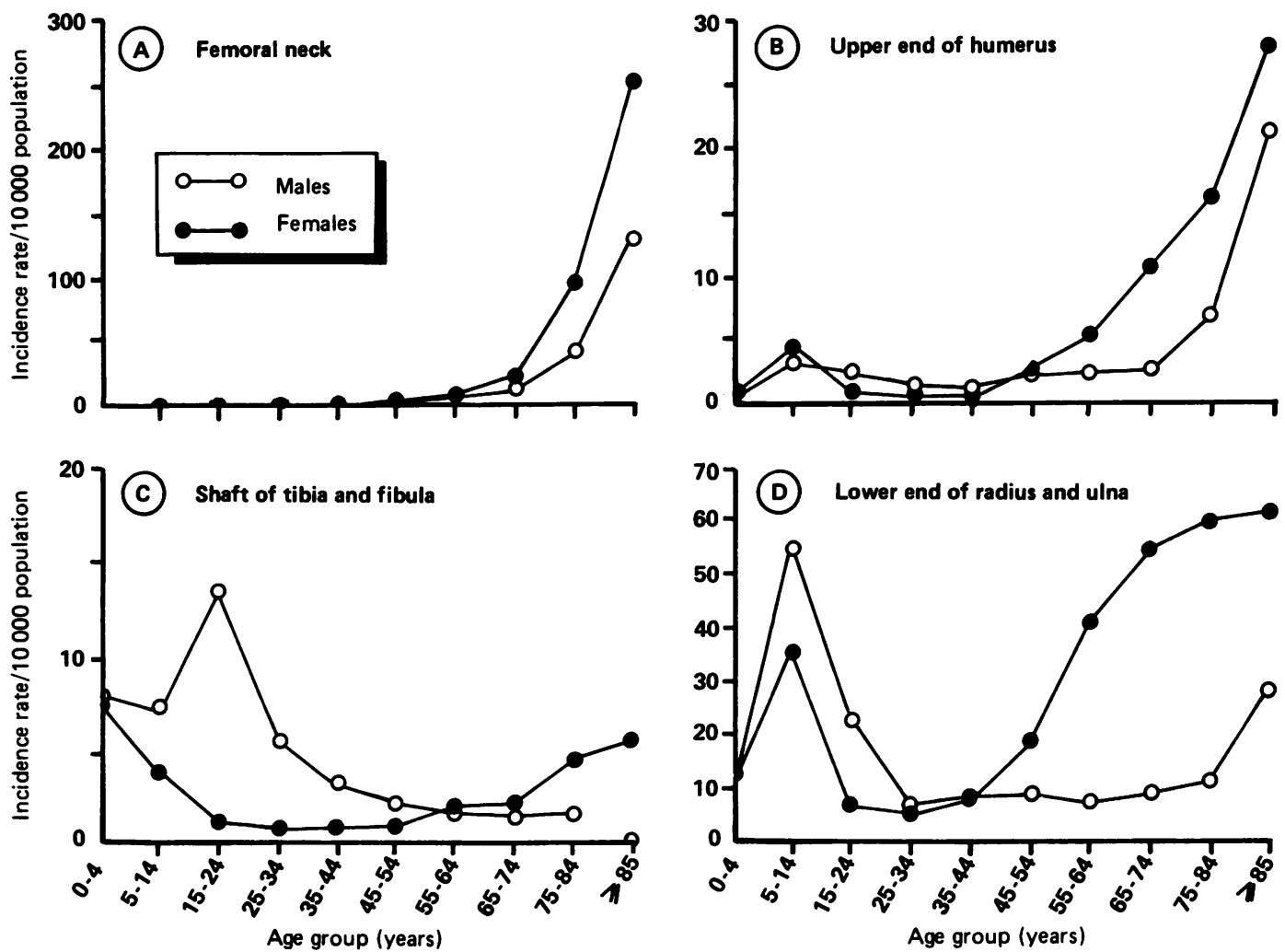

Figure 2 Age and sex specific average annual fracture incidence rates (per 10000 population) at selected sites.

distribution (fig 2B). Fractures of the shaft of the tibia and fibula (fig 2C) and of the lower end of the radius and ulna (fig 2D) displayed a markedly different pattern, with prominent peaks of incidence again in young males, with a higher incidence of female fractures in the older age groups.

The relationship between incidence of fractures at each site and the age and sex of those sustaining the fractures is also shown in fig 3, where the log ratio of the incidence rate for males to females is compared for two broad age bands (under and over 55 years) with $95 \%$ confidence intervals.

In all fractures there was an excess incidence of fracture in males amongst those under 55 years of age (male to female ratio of more than 1 ) and in all groups there was a fall in the male to female ratio above the age of 55 . However two broad patterns emerge within this consistency. In the first pattern (fig $3 \mathrm{~A}$ ), while there was a fall in the ratio, the mean male to female ratio remained greater than 1

Table I Average annual incidence (per 10000 population) of fractures at different sites

\begin{tabular}{|c|c|c|c|}
\hline Fracture sites & Males & Females & Both Sexes \\
\hline $\begin{array}{l}\text { Radius and ulna (lower end) } \\
\text { Neck of femur } \\
\text { Ankle } \\
\text { Humerus (other than upper end) } \\
\text { Metacarpals } \\
\text { Tarsals and metatarsals } \\
\text { Radius and ulna (upper end and shaft) } \\
\text { Clavicle } \\
\text { Skull } \\
\text { Tibia and fibula (shaft) } \\
\text { Carpals } \\
\text { Femoral shaft } \\
\text { Tibia and fibula (upper end) } \\
\text { Chest } \\
\text { Spine } \\
\text { Pelvis } \\
\text { Patella } \\
\text { Phalanges of foot } \\
\text { Scapula } \\
\text { Humerus (upper end) } \\
\text { All other sites }\end{array}$ & $\begin{array}{r}18 \cdot 2 \\
3.9 \\
8 \cdot 7 \\
3.6 \\
11.7 \\
7 \cdot 3 \\
6 \cdot 1 \\
6 \cdot 7 \\
6.9 \\
5 \cdot 8 \\
4 \cdot 4 \\
3.4 \\
3.4 \\
2.5 \\
1.9 \\
1.6 \\
1.4 \\
1.5 \\
0.8 \\
2.2 \\
17.0\end{array}$ & $\begin{array}{r}24 \cdot 3 \\
12 \cdot 1 \\
6.5 \\
3.6 \\
1.9 \\
5 \cdot 2 \\
5.5 \\
3 \cdot 2 \\
2 \cdot 3 \\
2 \cdot 4 \\
1.9 \\
2 \cdot 9 \\
1.9 \\
1 \cdot 1 \\
1 \cdot 2 \\
1.8 \\
0 \cdot 8 \\
0.7 \\
0 \cdot 2 \\
4 \cdot 0 \\
6.0\end{array}$ & $\begin{array}{r}21 \cdot 3 \\
8 \cdot 1 \\
7 \cdot 6 \\
3 \cdot 6 \\
6 \cdot 7 \\
6 \cdot 2 \\
5 \cdot 8 \\
4 \cdot 9 \\
4 \cdot 6 \\
4 \cdot 1 \\
3 \cdot 1 \\
3 \cdot 1 \\
2 \cdot 6 \\
1 \cdot 8 \\
1 \cdot 6 \\
1 \cdot 7 \\
1 \cdot 1 \\
1 \cdot 1 \\
0 \cdot 5 \\
3 \cdot 1 \\
12 \cdot 0\end{array}$ \\
\hline All sites & $100 \cdot 2$ & 81.0 & 90.5 \\
\hline
\end{tabular}

over the age of 55 . In the second pattern (fig 3B) there was reversal of the male to female ratio before and after 55 years of age.

\section{Discussion}

This paper describes the first population based study of fracture incidence in all ages in the United Kingdom. The only similar previous study reported 20 years ago and was limited to patients of 35 years of age and over. ${ }^{2}$ Studies from other countries have provided data on specific fractures, but the different social and environmental status of these populations limit their applicability to British populations. ${ }^{3-5}$

We have confirmed the previously recognised ${ }^{2} 8$ variation in fracture incidence with age and sex: an early peak in young males and females, with this early peak extending into the 15-24 age group amongst males, but with the incidence already falling in females of this age. In both sexes there was a subsequent secondary rise in incidence with increasing age. In women the increase begins in 45-54 year age group, but was delayed in men until the 75-84 year age group.

Although data on cause of fracture did not form part of the present study, this incidence pattern reflects the established contributory factors, ${ }^{3}$ with sports, industrial and road traffic accidents being important in the younger age groups (explaining the male preponderance), while in the older age groups osteoporotic change and falls become predominant.

The examination of the risk of fracture at particular sites by particular age groups in men and women emphasised the consistent excess incidence of fractures in older women, but shows marked differences in the patterns in younger age groups. Fractures of the shaft of the tibia and fibula are, par excellence, an injury of young men, 


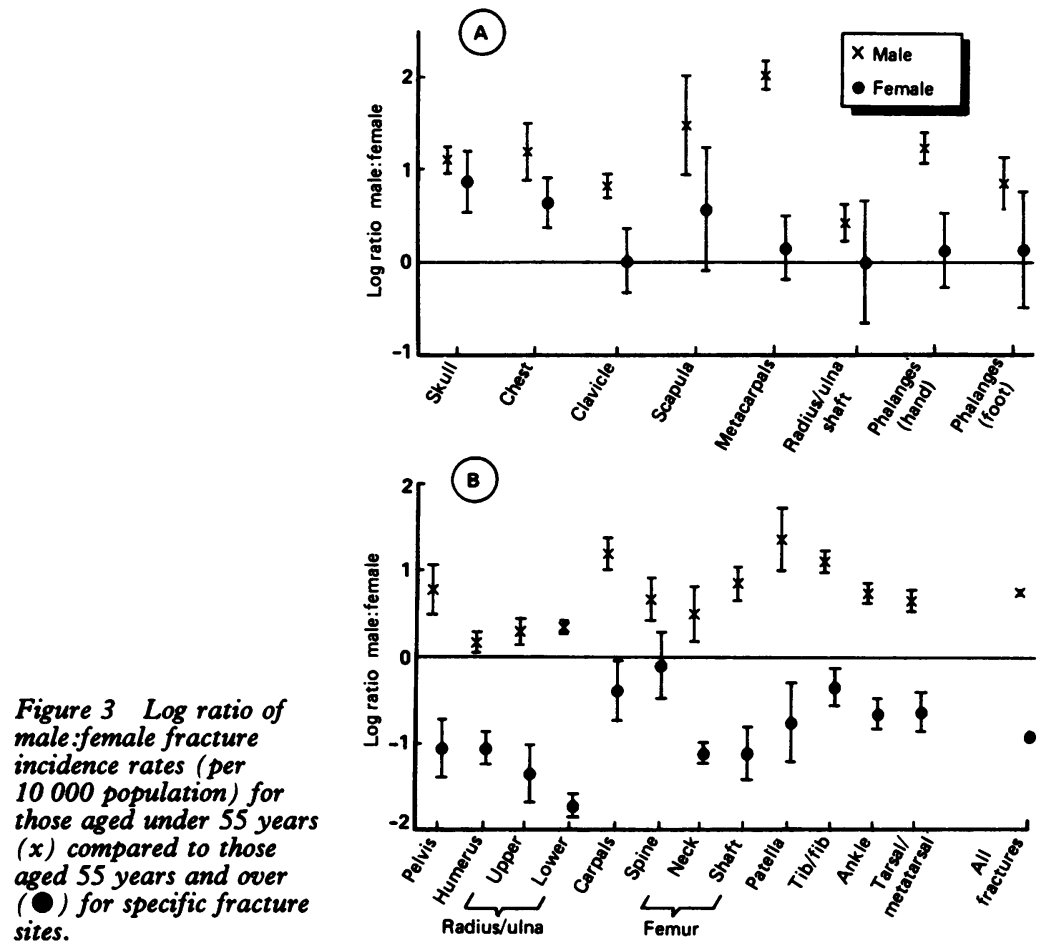

sites.
Table II Comparison of age specific average annual incidence rates (per 10000 population) of fractures at all sites amongst the male and female population aged over 35 years in Leicestershire (19801982), Dundee and Oxford (1954-1958) presumably resulting from contact sports and road traffic accidents, especially motorcyle accidents, while fractures of the lower end of the radius and ulna, where a common mechanism is a fall on the outstretched hand, are only slightly more common in younger men than younger women.

Fractures of the neck of femur and upper humerus show a very low incidence in the young with a late rise in incidence in both sexes, presumably associated with factors already described. This latter rise in incidence is mirrored in the later age groups in fracture of the lower end of the radius and ulna.

Conclusions drawn from comparisons with other population based studies of fracture incidence must be made with caution. Factors such as the underlying variation in demographic, socioeconomic, and climatic conditions may be important and degree of ascertainment may vary between different studies. In addition the prevalence of risk factors such as osteoporosis in the defined populations are not available.

However, comparison with the earlier UK based study of those aged 35 years and over in Oxford and Dundee ${ }^{2}$ reveals interesting features. The annual incidence rates of all fractures in both studies is shown in table II. The major differences were of lower incidence rates in women under 65 years of age and men under 75 years in Leicestershire compared with the combined rates in the Dundee/Oxford study, and higher incidence rates in women and men over 75 . The overall experience for women in Leicestershire in 1980-82 compared closely to that of women in Dundee in 1954-58, but there was still a marked discrepancy in age specific rates in men in most age groups compared to both Oxford and Dundee. Looking at age specific incidence for individual fracture sites, the major differences compared to the earlier UK study were higher annual incidence in the Leicestershire population for the following fracture sites and age groups: fractured neck of femur (in the older age groups in both sexes); rib fractures (in both sexes and all age groups); humeral fracture, excluding the upper end (in both sexes and all age groups); tibial and fibular fractures (in women in the older age groups); and femoral shaft fractures (in women in the older age groups).

Thus, the age related incidence appears to have increased in the older age groups in both sexes for all fractures. While it is possible that this is artefactual, a considerable contribution to the apparent rise comes from the higher incidence of fractured neck of femur, and this is a phenomenon that has been reported by others both in the United Kingdom and elsewhere. ${ }^{4910}$ It has been suggested that the increase in population incidence of fractured neck of femur is due to both an increase in the proportion of elderly people as well as an increase in the age specific incidence of fractures in this group. The explanation for this remains unclear, but perhaps the population now surviving to an older age is more prone to fracture than their equivalent age group in the past. Potential factors could be increased survival of the frail elderly, with increased tendency to falls and osteoporosis. The influence of increasing drug treatment of the elderly is another potential factor.

Comparison of our data with studies from Rochester, USA, on specific fracture sites, limbs, ${ }^{3}$ pelvis, ${ }^{11}$ and ankle ${ }^{12}$ shows a higher fracture incidence in this North American population which was also seen when its rates were compared to the UK population of the Dundee/Oxford study, a finding which the authors of the reports from Rochester suggested was due to differences in ascertainment. ${ }^{3} \mathrm{We}$ consider this to be an unlikely explanation for the difference between Rochester and Leicestershire, given our belief that we had achieved high ascertainment of fracture occurrence. Therefore the higher incidence in Rochester remains to be explained. Similarly, site specific fractures in Scandinavian studies give overall higher incidence rates for distal forearm, ${ }^{13}{ }^{14}$ proximal humerus, ${ }^{15}$ and hip fractures, ${ }^{16}$ a further international difference which is unexplained.

The pattern of change in male to female ratio below and above the age of 55 for difference fracture sites is striking. The fall in male to female

\begin{tabular}{|c|c|c|c|c|c|c|c|c|}
\hline \multirow[b]{2}{*}{ Age groups } & \multicolumn{4}{|l|}{ Males } & \multicolumn{4}{|l|}{ Females } \\
\hline & $\begin{array}{l}\text { Leicester- } \\
\text { shire }\end{array}$ & Dundee & Oxford & $\begin{array}{l}\text { Oxford } \mathcal{E} \\
\text { Dundee } \\
\text { combined }\end{array}$ & $\begin{array}{l}\text { Leicester- } \\
\text { shire }\end{array}$ & Dundee & Oxford & $\begin{array}{l}\text { Oxford E } \\
\text { Dundee } \\
\text { combined }\end{array}$ \\
\hline $\begin{array}{l}35-44 \\
45-54 \\
55-64 \\
65-74 \\
75-84 \\
85 \text { and over }\end{array}$ & $\begin{array}{r}63 \\
57 \\
50 \\
53 \\
105 \\
288\end{array}$ & $\begin{array}{r}115 \\
120 \\
99 \\
81 \\
102 \\
230\end{array}$ & $\begin{array}{r}74 \\
105 \\
93 \\
69 \\
84 \\
159\end{array}$ & $\begin{array}{c}94.5 \\
112.5 \\
96 \\
75 \\
93 \\
194.5\end{array}$ & $\begin{array}{r}31 \\
54 \\
93 \\
137 \\
249 \\
458\end{array}$ & $\begin{array}{r}37 \\
81 \\
113 \\
132 \\
190 \\
456\end{array}$ & $\begin{array}{r}32 \\
72 \\
114 \\
125 \\
186 \\
281\end{array}$ & $\begin{array}{r}34.5 \\
76 \cdot 5 \\
113.5 \\
128 \cdot 5 \\
188 \\
368.5\end{array}$ \\
\hline
\end{tabular}


ratio across all fracture sites reinforces the view that older women are more susceptible to fracture than men. However, the two patterns of change in ratio do not enable clear conclusions to be drawn about causality. Trabecular bone is thought to be more susceptible to postmenopausal related osteoporosis than cortical bone ${ }^{17}$ but there appears to be no consistency of association with bone type within the two patterns of change of ratio. However the consistency of the fall in the male to female ratio in the present study reinforces the fact that there is an age related risk of fracture associated with the female sex.

Two major explanations have been proposed for the shift towards a female preponderance of fracture incidence with advancing years. Firstly, the influence of osteoporotic change: average bone mass tends to decrease after the fourth or fifth decade of life in all populations studied to date and would appear to be an almost universal phenomenon of aging. ${ }^{18}$ There is good evidence that osteoporosis predisposes to fracture, at least of the hip, ${ }^{19}$ vertebrae, ${ }^{20}$ distal forearm, ${ }^{21}$ humerus, ${ }^{22}$ and pelvis. ${ }^{11}$ The increasing incidence of fracture in older women may be related to a more rapid reduction in bone mass following the menopause and related to hormonal change. ${ }^{23}$

However, the relationship between bone density and risk of fracture is not simple. Thus a recent study has confirmed an increased risk of femoral neck fracture with reduced femoral neck bone mass, but the steep increase in risk in those under 75 years of age was in contrast to a small increase in risk over 75 years of age. ${ }^{24}$ This study suggested that neuromuscular factors, which protect the skeleton from trauma might be more important in the older age groups.

Studies relating bone mass to fracture show a wide overlap between patients with fractures and controls suggesting that factors other than osteoporotic change are important. ${ }^{25-27}$ One further factor is the influence of falls. Even accepting an increase in risk of fractures secondary to osteoporotic change with age, there is still a requirement for stress if a fracture is to occur. There is evidence that an increase in falls with age is important and that women may fall more than men, producing a form of double jeopardy. ${ }^{28} \mathrm{~A}$ recent study suggests that the increase in falls in women may occur perimenopausally. ${ }^{29}$ Other factors associated with an increased risk of falling in the elderly include weak hand grip strength, impaired mobility, use of non-phenothiazine tranquillizers, living alone, recent weight loss, and physical disability, with hand grip and mobility having the greatest effect. ${ }^{30}$ Thus neuromuscular deterioration may both increase the risk of trauma and adversely affect skeletal protection, highlighting the complicated relationship between osteoporosis, falls, and fracture susceptibility.

Our data are consistent with earlier observations. One could propose that the increasing incidence with age is related to both falls and osteoporotic change and that the fall in male to female ratio over the age of 55 is largely due to a steep increase in osteoporosis in women postmenopausally, with subsequent age related and parallel osteoporotic change in both sexes. ${ }^{31}$ In addition the influence of falls and neuromuscular deterioration in the elderly must be considered.
Examination of the factors involved in those fractures where there is a wide difference in the male to female ratio below and above 55 years of age compared to those where there is less of a difference would be an important starting point for further epidemiological studies aimed at elucidation of the aetiology of these important injuries.

Finally, this study adds further weight to the evidence linking fracture incidence to potentially preventable factors responsible for a major public health problem.

We are grateful to Consultant members of the Division of Orthopaedics in Leicestershire for their help in gathering the data and to David Clayton for advice in the analysis.

1 Department of Health and Social Security. 1985 Hospital inpatient enquiry. Series MB4 No 26. London: HMSO, 1988. 2 Knowelden J, Buhr AJ, Dunbar O. Incidence of fractures in Knowelden J, Buhr AJ, Dunbar O. Incidence of fractures in
persons over 35 years of age. Br $\mathcal{F}$ Prev Soc Med 1964; 18: persons

3 Garraway WM, Stauffer RN, Kurland LT, O'Fallon WM. Limb fractures in a defined population. 1. Frequency and distribution. Mayo Clin Proc 1979; 54: 701-7.

4 Melton LJ, O'Fallon WM, Riggs BL. Secular trends in the incidence of hip fractures. Calcif Tissue Int 1987; 41: 57-64.

5 Jensen GF, Christiansen C, Boesen J, Hegedus V, Transbol I. Epidemiology of postmenopausal spinal and long bone fractures. Clin Orthop 1982; 166: 75-81.

6 World Health Organization. Manual of the international classification of diseases, injuries and causes of death. Geneva: WHO, 1977.

7 Melton LJ, Kan SH, Frye MA, Wahner HW, O'Fallon WM, Riggs BL. Epidemiology of vertebral fractures in women. Riggs BL. Epidemiology of vertebral

8 Buhr AJ, Cooke A. Fracture patterns. Lancet 1959; i: 531-6.

9 Boyce WP, Vessey MP. Rising incidence of fracture of the proximal femur. Lancet 1985; i: 150-1.

10 Zetterberg C, Elmerson S, Andersson GBJ. Epidemiology of hip fractures in Goteburg, Sweden, 1940-1983. Clin Orthop 1984; 191: 43-52.

11 Melton LJ, Sampson JM, Morrey BF, Ilstrup DM. Epidemiological features of pelvic fractures. Clin Orthop 1981; 155: 43-7.

12 Daly PJ, Fitzgerald RH, Melton LJ, Ilstrup DM. Epidemiology of ankle fractures in Rochester, Minnesota. Acta Orthop Scand 1987; 58: 539-44.

13 Solgaard S, Petersen VS. Epidemiology of distal radius fractures. Acta Orthop Scand 1985; 56: 391-3.

14 Falch JA. Epidemiology of fractures of the distal forearm in Oslo, Norway. Acta Orthop Scand 1983; 54: 291-5.

15 Kristiansen B, Barford G, Bredsen J, Erin-Madsen J, Grum B, Horsnaes MW, Aalberg JR. Epidemiology of proximal humeral fractures Acta Orthop Scand 1987; 58: 75-7.

16 Falch JA, Ilebekk A, Slungaard U. Epidemiology of hip fractures in Norway. Acta Orthop Scand 1985; 56: 12-6.

17 Mazess RB. Noninvasive methods for quantitating trabecular bone. In: Avioli LV, ed. The osteoporotic syndrome. New York: Grune and Stratton, 1983.

18 Cummings SR, Kelsey JL, Nevitt MC, O'Dowd KJ. Epidemiology of osteoporosis and osteoporotic fractures. Epidemiol Rev 1985; 7: 178-208.

19 Alffram P. An epidemiological study of cervical and trochanteric fractures of the femur in an urban population. Acta Orthop Scand (suppl) 1964; 65: 1-109.

20 Arnold JS. Amount and quality of trabecular bone in osteoporotic vertebral fractures. Clin Endocrinol Metab 1973; 2: 221-38.

21 Alffram PA, Bauer CH. Epidemiology of fractures of the forearm: a biomechanical investigation of bone strength. $f$ Bone foint Surg 1962; 44A: 105-14.

22 Rose SH, Melton LJ, Morrey BF, Ilstrup DM, Riggs BL. Epidemiological features of humeral fractures. Clin Orthop 1982; 168: 24-30.

23 Nordin BEC. Osteoporosis with particular reference to the menopause. In: Avioli LV, ed. The osteoporotic syndrome. New York: Grune and Stratton, 1983: 13-43.

24 Cooper C, Barker DJP, Morris J, Briggs RSJ. Osteoporosis, falls, and age in fracture of the proximal femur. $\mathrm{Br}$ Med $\mathcal{F}$ 1987; 295: 13-5.

25 Aaron JE, Gallagher JC, Anderson J, et al. Frequency of osteomalacia and osteoporosis in fractures of the proximal fernur. Lancet 1974; i: 229-33.

26 Horsman A, Simpson M, Speed R. Cortical and trabecular bone status in elderly women with femoral neck fracture. bone status in elderly women
Clin Orthop 1982; 166: 143-51.

27 Nilsson BE, Westlin NE. The bone mineral content in the forearm of women with Colles' fracture. Act Orthop Scand 1974; 45: 836-44.

28 Prudham D, Grimley Evans J. Factors associated with falls in the elderly: a community study. Age Ageing 1981; 10: 141-6. Winner SJ, Morgan CA, Grimley Evans J. Perimenopausal risk of falling and incidence of distal forearm fracture. $\mathrm{Br}$ Med $f$ 1989; 298: 1486-8.

30 Wickham C, Cooper C, Margetts BM, Barker DJP. Muscle strength, activity, housing and the risk of falls in elderly people. Age Ageing 1989: 18: 47-51.

31 Riggs BL, Melton LJ. Evidence for two distinct syndromes of involutional osteoporosis $A m$ I Med 1983; 75: 899-901. 